\title{
Solid-state NMR crystallography analysis of Lorlatinib, an active pharmaceutical ingredient
}

\author{
Zainab Rehman \\ University of Warwick, Coventry, United Kingdom; \\ zainab.rehman@warwick.ac.uk
}

\begin{abstract}
A NMR crystallography study is presented for Lorlatinib, an active pharmaceutical ingredient (API) used in the treatment of lung cancer. Various one-dimensional and two-dimensional solid-state magic-angle spinning (MAS) NMR experiments have been performed that provide the ${ }^{1} \mathrm{H}$ and ${ }^{13} \mathrm{C}$ chemical shifts as well as the ${ }^{14} \mathrm{~N}$ shifts. $\mathrm{A}{ }^{1} \mathrm{H}(\mathrm{DQ}){ }^{1} \mathrm{H}(\mathrm{SQ})$ MAS NMR spectrum was obtained with $\mathrm{BaBa}$ recoupling that reveals proton-proton proximities interactions between the ${ }^{1} \mathrm{H}$ nuclei that are typically within $3.5 \AA$ of each other. A ${ }^{14} \mathrm{~N}-{ }^{1} \mathrm{H}$ HMQC MAS NMR spectrum reveals that one of the $\mathrm{NH}_{2}{ }^{1} \mathrm{H}$ resonances has a significantly low ${ }^{1} \mathrm{H}$ chemical shift; this is interpreted in terms of differences in intermolecular hydrogen bonding. Enhanced resolution is observed in two-dimensional ${ }^{1} \mathrm{H}-{ }^{13} \mathrm{C}$ heteronuclear MAS NMR experiments at $1 \mathrm{GHz}$.
\end{abstract}

Keywords: Solid State NMR; Pharmaceuticals 